\title{
Radiographic features of oral cholecystograms of 448 symptomatic gallstone patients: implications for nonsurgical therapy
}

\author{
Peter W. Plaisier*a, Koen Brakel ${ }^{b}$, René L. van der Hul ${ }^{a}$, Hajo A. Bruining ${ }^{\text {a }}$ \\ "Department of Surgery, ${ }^{b}$ Department of Radiology, University Hospital 'Dijkzigt', Erasmus University Rotterdam, Dr. Molewaterplein 40, \\ 3015 GD Rotterdam. Netherlands
}

(Received 15 June 1993: revision accepted 1 October 1993)

\begin{abstract}
Since radiographic findings on oral cholecystography (OCG) have implications for the eligibility for nonsurgical therapy of elderly patients, we investigated the OCGs of 448 symptomatic gallstone patients ( 109 male, 339 female; mean age, $49.8 \pm 14$ (range, 21-88)). Opacification of the gallbladder was found in 323 cases $(72.1 \%)$. Calcifications of gallstones were found in 85 opacified gallbladders $(26.3 \%)$. Solitary and multiple stones were calcified in $35.3 \%$ and $18.2 \%$, respectively $(P<0.0005)$. When divided into two groups ( $\leq 40$ years and $>40$ years), there was a significant increase in calcifications $(P<0.02)$ and a non-significant increase in opacification with increasing age. It is concluded that age is a determinant for calcification of gallstones and not opacification of the gallbladder. Since multiple stones are proportionately observed more in clinical studies than in epidemiologic studies, it is suggested that multiplicity of stones predisposes to biliary complaints. That solitary stones are more likely to be calcified than multiple stones, adds to the hypothesis that solitary and multiple stones have a different pathogenesis. Elderly patients, in whom nonsurgical therapy is most likely to be indicated and cost-effective, are less likely to be suitable for this form of treatment, since age is a determinant for stone calcification.
\end{abstract}

Key words: Gallbladder, lithotripsy; Gallbladder, radiography; Lithotripsy

\section{Introduction}

The development of oral cholecystography (OCG) is one of the milestones in the history of roentgenology [1]. OCG has been the unchallenged standard in the diagnosis of gallbladder disease for half a century, but less than five years after the introduction of ultrasonography (US), OCG disappeared almost entirely from clinical practice. The introduction of several nonsurgical treatment modalities for gallstone disease [2-8], resurrected the use of OCG for it can provide information on stone composition and patency of the cystic duct.

We analysed the OCGs of 448 symptomatic gallstone patients for their radiographic features. The aim of this study was twofold. First, we wanted to investigate if age is a determinant of calcification of gallstones and nonopacification of the gallbladder, because this would

\footnotetext{
* Corresponding author.
}

have implications for the eligibility for nonsurgical therapy of elderly patients. Second, we wanted to investigate to what extent our clinical findings agreed with epidemiologic findings. This paper reports our findings.

\section{Patients and methods}

In 1988 a surgical outpatient biliary clinic was started. It was especially designed to select patients for alternative treatment modalities for gallstone disease, such as orally administered bile acids [2,3], contact dissolution $[4,5]$, extracorporeal shock wave lithotripsy (ESWL) $[6,7]$ and rotary contact lithotripsy [8].

In the period April 1st, 1988 to April 1st, 1992, 774 patients visited this clinic. All patients were analysed according to protocol: patient's history, physical examination and (if patients were considered symptomatic) laboratory tests and radiologic examination. Patients were considered symptomatic only, if they had experi- 
enced one or more episodes of abdominal pain (usually epigastric or right upper quadrant) lasting more than 15 min but less than $5 \mathrm{~h}$, according to the Roma Working Team definition [9].

Radiologic examination consisted of US and OCG. Calcifications were only recorded in visualised gallbladders, analogously to the GREPCO study [10]. Results of recent examinations done elsewhere, were not repeated and used in this study. An OCG was not performed, when the patient refused a nonsurgical therapeutic option or if previous US examination excluded the patient by our ESWL entry criteria ( $>10$ stones, stones with a diameter $<5 \mathrm{~mm}$, common bile duct stones, aneurysms or cysts in the shock wave path and pregnancy) [7].

One-hundred thirteen patients $(14.6 \%)$ were excluded from OCG, because they had no biliary symptoms. Of the 661 symptomatic patients, 213 patients $(32.2 \%)$ had no OCG performed because they preferred cholecystectomy. OCG was performed after intake of iocematic acid the evening before the examination. Intake of Cholebrine $^{\circledast}$ (iocematic acid) was according to body weight: $<60 \mathrm{~kg}, 3.00 \mathrm{~g}(1.86 \mathrm{~g}) ; 60-90 \mathrm{~kg}, 4.50 \mathrm{~g}(2.79$ $\mathrm{g}) ;>90 \mathrm{~kg}, 6.00 \mathrm{~g}(3.72 \mathrm{~g})$. Cholebrine ${ }^{\circledR}$ was taken orally in two steps with an interval of $1 \mathrm{~h}$, with some water, after which the patient was not allowed to eat, drink or smoke. Intake of Cholebrine ${ }^{\circledR}$ was planned in such a way, that fasting time was approximately $12 \mathrm{~h}$.

Due to logistical reasons we were not able to provide repeat doses in the case of nonvisualisation of the gallbladder. However, it has been demonstrated that in patients in whom normal opacification occurs after a repeat dose, the initial dose already gave a faint visualisation of the gallbladder [11]. Therefore, we categorised faint visualisation as opacification being present.

All data were recorded on standardised forms without knowledge of previous examinations. On these standardised forms used for OCG the radiologist recorded whether there was opacification (Yes/No), the number of gallstones $(0,1,2,3,4,5,6-10,>10)$, the diameter of the largest stone (in $\mathrm{mm}$ ), whether the stones were calcificied (Yes/No) and if there was buoyancy (the presence of floating stones, Yes/No). In addition, if present, the sort of calcification (core, $\operatorname{rim}<2 \mathrm{~mm}$, rim $>2$ $\mathrm{mm}$, total) was recorded. Finally, in the case the gallbladder did not opacify, whether there was contrast in the small bowels (Yes/No) to determine the patient's compliance. In the case of nonspherical stones the largest diameter was recorded. Measurements of stone size were corrected for an empirically determined magnification factor of 1.3.

Statistical analysis was done by means of regression analysis, the Chi-square test for trends in proportions, and the test for differences between proportions assuming binomial distributions.

\section{Results}

Four hundred and forty eight patients (109 male, 339 female; mean age, $49.8 \pm 14$ (range, 21-88)) underwent OCG. Opacification was found in 323 cases $(72.1 \%)$ and nonvisualisation in $125(27.9 \%)$. Calcifications were found in 85 cases of 323 visualised gallbladders $(26.3 \%)$. These results are summarised in Table 1 together with the calcification patterns.

Between the sexes there was no significant difference in opacification $(69.7 \%$ (male) vs. $74.6 \%$ (female; $P=0.31)$ and calcifications $(31.6 \%$ (male/male) vs. $24.1 \%$ (fernale); $P=0.19$ ).

Stones were calcified in $35.3 \%$ of the solitary stones (36/102) and in $18.2 \%$ of multiple stones (49/269) $(P<$ 0.0005 ). Mean diameter of the largest stone was on OCG $17.3 \pm 11 \mathrm{~mm}$ (range, 3-65); median, $15 \mathrm{~mm}$.

The distribution of number of stones is depicted in Table 2. With US, solitary stones were found in $30.1 \%$ of all 448 cases and $33.1 \%$ of the 323 gallbladders, visualising at OCG. Mean diameter of the largest stone measured with US, was $14.2 \pm 8 \mathrm{~mm}$ (range, 3-45); median, $12 \mathrm{~mm}$.

Patients $\leq 40$ years and $>40$ years had opacified gallbladders in $69.3 \%(88 / 127)$ and $73.2 \%(235 / 321)$ of the cases, respectively $(P=0.40)$. Patients $\leq 40$ years and $>40$ years had calcified stones in opacified gallbladders in $16.9 \%(15 / 89)$ and $29.9 \%(70 / 234)$ of the cases, respectively $(P<0.02)$.

\section{Discussion}

US is the preferred diagnostic tool for detecting gallstones, for it is noninvasive and, unlike OCG, simple to perform, lacks ionising radiation and is independent of hepatic function [12,13]. Moreover, US is slightly more sensitive than OCG [14] (Table 2). Still, OCG is very reliable in determining gallstone size and number

Table 1

Gallbladder opacification, stone calcification and buoyancy recorded at oral cholecystography in $\mathbf{4 4 8}$ symptomatic gallstone patients

\begin{tabular}{|c|c|c|}
\hline Feature & $\begin{array}{l}\text { No. of } \\
\text { patients }\end{array}$ & Percentage \\
\hline \multicolumn{3}{|l|}{ Gallbladder } \\
\hline Opacification & 323 & 72.1 \\
\hline \multicolumn{3}{|l|}{ Gallstones } \\
\hline Calcification & 85 & 26.3 \\
\hline Completely & 30 & 35.3 \\
\hline $\operatorname{Rim} \leq 2 \mathrm{~mm}$ & 24 & 28.2 \\
\hline $\operatorname{Rim}>2 \mathrm{~mm}$ & 13 & 15.3 \\
\hline Core & 13 & 15.3 \\
\hline Not recorded & 5 & 5.9 \\
\hline Buoyancy & 20 & 4.5 \\
\hline
\end{tabular}

"OCG performed in another hospital. 
Table 2

Distribution of number of stones at oral cholecystography (OCG) and the corresponding findings at ultrasonography (US) in 323 visualised gallbladders of 448 symptomatic patients

\begin{tabular}{lcc}
\hline No. of stones & $\begin{array}{l}\text { No. of patients } \\
\text { on OCG }(\%)\end{array}$ & $\begin{array}{l}\text { No. of patients on } \\
\text { US }(\%)\end{array}$ \\
\hline 0 & $54(16.7)$ & $18(5.6)^{\mathrm{a}}$ \\
1 & $102(31.6)$ & $107(33.1)$ \\
2 & $41(12.7)$ & $41(12.7)$ \\
3 & $13(4.0)$ & $20(6.2)$ \\
4 & $12(3.7)$ & $11(3.4)$ \\
5 & $8(2.5)$ & $23(7.1)$ \\
$6-10$ & $24(7.4)$ & $27(8.4)$ \\
$>10$ & $57(17.6)$ & $65(20.1)$ \\
Not specifically & $12(3.7)$ & $11(3.4)$ \\
$\quad$ stated & & \\
& $323(99.9)$ & $323(100.0)$ \\
Total &
\end{tabular}

${ }^{a}$ Grit (concretions $<3 \mathrm{~mm}$ ). 6; polyps. 4; sludge, 2; adenomyomatosis, 1; passed stones, 5 .

[14]. OCG also provides information on the functional state of the gallbladder, information which is necessary for several nonsurgical treatment modalities for symptomatic gallstones.

We analysed the radiographic findings of 448 symptomatic gallstone patients. It is one of the largest prospective clinical studies available in the US era. Moreover, these data were double-checked with US in all cases. That different radiologists interpreted the OCGs, probably did not influence results, since it has been demonstrated that there is little inter-observer variety in assessment of visualisation of the gallbladder and opaqueness of gallstones [10].

We found an overall opacification rate of $72.1 \%$, which is comparable with two epidemiologic studies in Italy $[10,15]$. Although Mujahed et al. found an overall visualisation rate of $91.7 \%$, it must be borne in mind that they used a different OCG regimen [16]: at day 1 of their 2-day examination, $75.2 \%$ of the gallbladders opacified which is indeed comparable with our data. We also found that age is not a determinant of visualisation, which was also found by the Rome group [10].

We demonstrated an overall calcification rate of $26.3 \%$, a percentage also largely comparable with the Rome group, which found radiopacity in $29.1 \%$ of the cases [10]. It is also in accordance with the clinical impression that radiolucent prevail over radiopaque stones [17]. We found that the elderly are more likely to have calcified gallstones than younger patients, which is in accordance with Bell's chemical analysis of gallstones [18]. However, unlike Bell and others [19], we, like the GREPCO study, were not able to demonstrate a significant larger calcification rate in men than in women. This is most probably caused by the fact that radiologic studies do not entirely reflect the chemical structure of the gallstones, since not all calcifications are shown at radiography [20]. On the other hand, the discrepancy may be due to selection. Bell found a radiopaqueness in 50\% of patients coming to cholecystectomy and in his paper he had already noted that this rate was considerably higher than reported elsewhere [18]. He argued that radiopaque stones were more likely to be detected than radiolucent stones, which was true since his study was performed in the pre-US era. Sutor and Wooley also used gallstones removed at cholecystectomy [19], which possibly explains the difference.

We found that multiple stones prevail over solitary stones in both OCG and US, which is in accordance with the clinical impression [17]. This was also found in another clinical study performed by Brink, who investigated the contents of extirpated gallbladders [21]. Epidemiologic studies, however, demonstrate solitary stones in $40.5-50.9 \%$ of the OCGs $[10,22]$ and $45 \%$ of the USs [23]. This discrepancy between clinical and epidemiologic studies suggests that multiple stones are more likely to cause biliary symptoms than solitary stones. This impression is in accordance with the findings of the National Cooperative Gallstone Study. where patients with multiple stones had more biliary pain before entering the study and were more likely to develop symptoms during the prospective follow-up [24].

Finally, to our knowledge, we are the first to report on the finding that solitary stones are calcified more often than multiple stones, a finding which adds to the hypothesis that solitary and multiple stones have different etiologies [25].

Our finding that elderly patients are more likely to have calcified gallstones implies that these patients are less likely to profit from nonsurgical therapy. First. because all sorts of calcifications exclude them from oral and contact dissolution therapy [2-5]. Second, because calcifications of $>2 \mathrm{~mm}$ are contraindicated for ESWL [6,7], and third, because stones with a calcified rim $\leq 2$ mm are even less likely to be cleared with ESWL than noncalcified stones [26]. In contrast to this, is the fact that rotary contact lithotripsy is able to treat all sorts of stones, including calcified ones [8]. However, this form of treatment is invasive and not readily available in most clinics [27].

That elderly patients are less likely to be suitable for nonsurgical therapy is regrettable. since in these patients this form of treatment is most likely to be indicated and cost-effective [28].

\section{References}

1 Cole WH. Historical features of gallbladder disease: an imaging symposium. Radiology 1961; 76: 354-375.

2 Danziger RG, Hofmann AF, Schoenfield LJ, Thistle JL. Dissolution of cholesterol gallstones by chenodeoxycholic acid. N Engl J Med 1972: 286: 1-8 
3 Bachrach WB, Hofmann AF. Ursodeoxycholic acid in the treatment of cholesterol cholelithiasis. Dig Dis Sci 1982; 27: 737-761, 833-856.

4 Thistle JL, May GR, Bender CE, Williams HJ, LeRoy AJ, Nelson PE, Peine CJ, Petersen BT, McCullough JE. Dissolution of cholesterol gallbladder stones by methyl tert-butyl ether administered by percutaneous transhepatic catheter. N Engl J Med 1989; 320: 633-639.

5 Leuschner U, Hellstern MD, Schmidt K, Fischer $H$, Guelduetuna S, Huebner K, Leuschner M. Gallstone dissolution with methyl tert-butyl ether in 120 patients. Efficacy and safety. Dig Dis Sci 1991; 36: 193-199.

6 Sackmann M, Pauletzki J, Sauerbruch T, Holl J, Schelling G, Paumgartner $G$. The Munich gallbladder lithotripsy study: results of the first 711 patients. Ann Intern Med 1991; 114: 290-296.

7 Toom R den, Vergunst H, Nijs HGT, Brakel K, Laméris JS, Terpstra OT. Electromagnetic shock wave lithotripsy of gallbladder stones: a wide range of inclusion criteria. Am J Gastroenterol 1992; 87: 498-503.

8 Miller FJ, Rose SC, Buchi KN, Hunter JG, Nah JE, Kensey KR. Percutaneous rotational contact biliary lithotripsy: initial clinical results with the Kensey Nash Lithotrite. Radiology 1991; 178: 781-785.

9 Paumgartner G, Carr-Locke DL, Roda E, Thistle JL. Biliary stones: non-surgical therapeutic approach. Gastroenterol Int 1988; 1: 17-24.

10 Rome group for the epidemiology and prevention of cholelithiasis (GREPCO). Radiologic appearance of gallstones and its relationship with biliary symptoms and awareness of having gallstones: observations during epidemiological studies. Dig Dis Sci 1987; 32: 349-353.

11 Berk RN. The problem of impaired first-dose vizualisation of the gallbladder. AJR 1971; 113: 186-188.

12 Simeone JF, Mueller PR, Ferruci JT. Nonsurgical therapy of gallstones: implications for imaging. AJR 1989; 152: 11-17.

13 Maglinte DDT, Torres WE, Laufer I. Oral cholecystography in contemporary gallstone imaging: a review. Radiology 1991; 178: 49-58.

14 Brakel K, Laméris JS, Nijs HGT, Ginai AZ, Terpstra OT. Accuracy of ultrasound and oral cholecystography in assessing the number and size of gallstones: implications for nonsurgical therapy. Br J Radiol 1992; 65: 779-783.

15 Barbara L, Sama C, Morselli Labate AM, Taroni F, Rusticali AG, Festi D, Sapio C, Roda E, Banterle C, Puci A, Formentini
F, Colasanti S, Nardiun F. A population study on the prevalence of gallstone disease. The Sirmione Study. Hepatology 1987; 7: 913-917.

16 Mujahed Z, Evans JA, Whalen JP. The nonopacified gallbladder on oral cholecystography. Radiology 1974: 112: 1-3.

17 Sherlock S. Diseases of the liver and biliary system, 7th edn. Oxford: Blackwell Scientific Publications, 1985.

I8 Bell GD, Dowling RH, Whitney B, Sutor DJ. The value of radiology in predicting gallstone type when selecting patients for medical treatment. Gut 1975; 16: 359-364.

19 Sutor DJ, Wooley SE. A statistical survey of the composition of gallstones in 8 countries. Gut 1971; 12: 55-61.

20 Brakel K, Laméris JS, Nijs HGT, Terpstra OT, Steen G, Blyenberg BG. Predicting gallstone composition with $\mathrm{CT}$ : in vivo and in vitro analysis. Radiology 1990; 174: 337-341.

21 Brink JA, Simeone JF, Mueller PR, Richter JM, Prien EL, Ferruci JT. Physical characteristics of gallstones removed at cholecystectomy: implications for extracorporeal shock wave lithotripsy. AJR 1998; 151: 927-931.

22 Bainton D, Davies GT, Evans KT, Gravelle IH. Gallbladder disease: prevalence in a South Wales industrial town. $\mathrm{N}$ Engl $\mathbf{J}$ Med 1976; 294: 1147-1149.

23 Jensen $\mathrm{KH}$, Jorgenson $\mathrm{T}$. Incidence of gallstones in a Danish population. Gastroenterology 1991; 100: 790-794.

24 Thistle JL, Cleary PA, Lachin JM, Tyor MP, Hersh T, The Steering Committee and The National Cooperative Gallstone Study. The natural history of cholelithiasis: the National Cooperative Gallstone Study. Ann Intern Med 1984; 10: 171-175.

25 Erpecum KJ van, Berge Henegouwen GP van, Stoelwinder B, Schmidt YMG, Willekens FL. Bile concentration is a key factor for nucleation of cholesterol crystals and cholesterol saturation index in gallbladder bile of gallstone patients. Hepatology 1990; 11: 1-6.

26 Schoenfield LJ, Berci G, Carnovale RL et al. The effect of ursodiol on the efficacy and safety of extracorporeal shock-wave lithotripsy of gallstones: The Dornier National Biliary Lithotripsy Study. N Engl J Med 1990; 323: 1239-1245.

27 Plaisier PW. Hul RL van der. Terpstra OT, Bruining HA. Current treatment modalities for gallstone disease. Am J Gastroenterol 1993; 88: 633-639.

28 Bass EB, Steinberg EP, Pitt HA, Saba GP, Lillemoe KD, Kafonek DR, Gadacz TR, Gordon TA, Anderson GF. Costeffectiveness of extracorporeal shock-wave lithotripsy versus cholecystectomy for symptomatic gallstones. Gastroenterology 1991; 101: 189-199. 